\title{
SPECIAL SECTION/ISSUE ON RACE, ETHNICITY, AND THE LAW
}

Law and Human Behavior announces a Special Section/Issue on Race, Ethnicity, and the Law. Theoretical and empirical articles on any aspect of race, ethnicity, law, and legal processes are invited. Deadline for completed manuscripts is February 1, 1993. Manuscript style may conform either to the Uniform System of Citation or to the Publication Manual of the American Psychological Association. Send four copies (three prepared for anonymous review) to: Valerie Hans and Ramiro Martinez, Jr., Editors, Special Section/Issue on Race, Ethnicity, and the Law, Criminal Justice Program, Department of Sociology and Criminal Justice, University of Delaware, Newark, DE, 19716. For more information please feel free to contact either of the editors (Valerie Hans: 302-831-8231; Ramiro Martinez, Jr.: 302-831-2291). 